
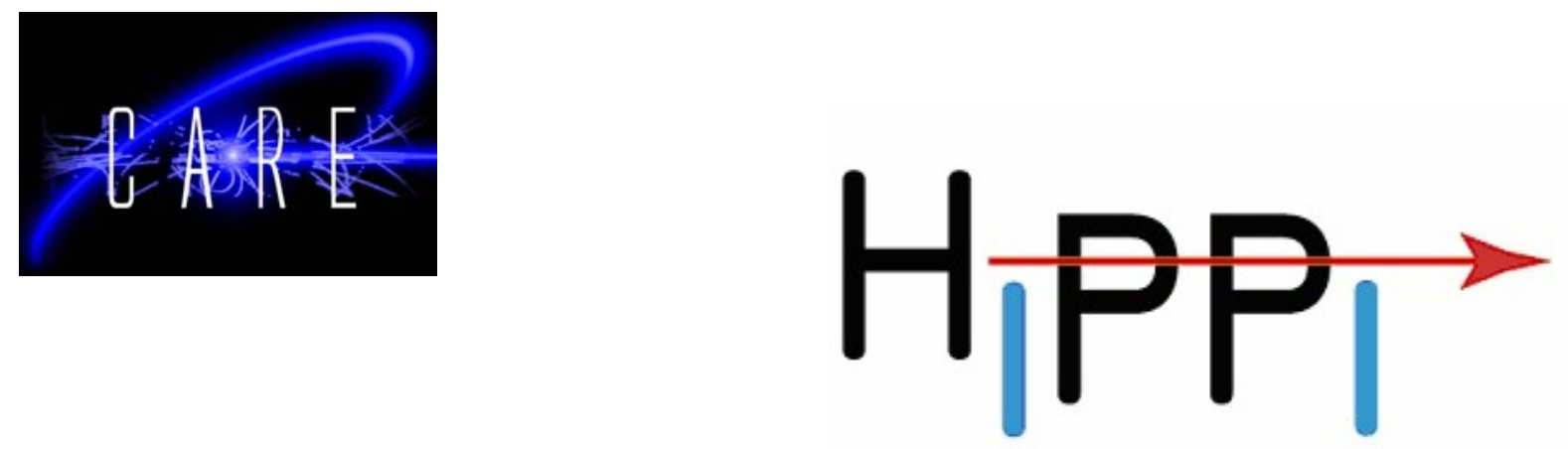

First Tests of the Superconducting CH-Structure

H. Podlech, H. Deitinghoff, H. Liebermann, H. Klein, U. Ratzinger, A. Sauer, R. Tiede Institut f"ur Angewandte Physik (IAP), University of Frankfurt, Germany

\begin{abstract}
The $\mathrm{CH}$ - or Crossbar H-structure is a new H-mode drift-tube structure operating in the $\mathrm{TE}_{210}$ mode. Due to its mechanical rigidity room temperature as well as superconducting cavities can be realized [1]. A superconducting version of the $\mathrm{CH}$-structure has been development at the IAP in Frankfurt, Germany. To prove the promising results obtained by simulations a 19cell, $352 \mathrm{MHz}(\beta=0.1$ ) prototype cavity has been designed and built. This $\mathrm{CH}$-prototype is the first superconducting low energy multi-cell cavity for the acceleration of protons and ions. The cavity has been tested at room temperature with an rf power of up to $300 \mathrm{~W} \mathrm{cW}$ and $2 \mathrm{~kW}$ pulsed. We present the first tests of the cavity as well as mechanical simulations.
\end{abstract}

Contribution to the PAC05, Knoxville, USA

Work supported by the European Community-Research Infrastructure Activity under the FP6 "Structuring the European Research Area" programme (CARE, contract number RII3-CT2003-506395). 


\title{
First Tests of the Superconducting CH-Structure *
}

\author{
H. Podlech, H. Deitinghoff, H. Liebermann, H. Klein, U. Ratzinger, A. Sauer, R. Tiede \\ Institut für Angewandte Physik (IAP), University of Frankfurt, Germany
}

\begin{abstract}
The $\mathrm{CH}$ - or Crossbar H-structure is a new H-mode drifttube structure operating in the $\mathrm{TE}_{210}$ mode. Due to its mechanical rigidity room temperature as well as superconducting cavities can be realized [1]. A superconducting version of the $\mathrm{CH}$-structure has been development at the IAP in Frankfurt, Germany. To prove the promising results optained by simulations a 19-cell, $352 \mathrm{MHz}(\beta=0.1)$ prototype cavity has been designed and built. This $\mathrm{CH}-$ prototype is the first superconducting low energy multi-cell cavity for the acceleration of protons and ions. The cavity has been tested at room temperature with an rf power of up to $300 \mathrm{~W} \mathrm{cw}$ and $2 \mathrm{~kW}$ pulsed. We present the first tests of the cavity as well as mechanical simulations.
\end{abstract}

\section{INTRODUCTION}

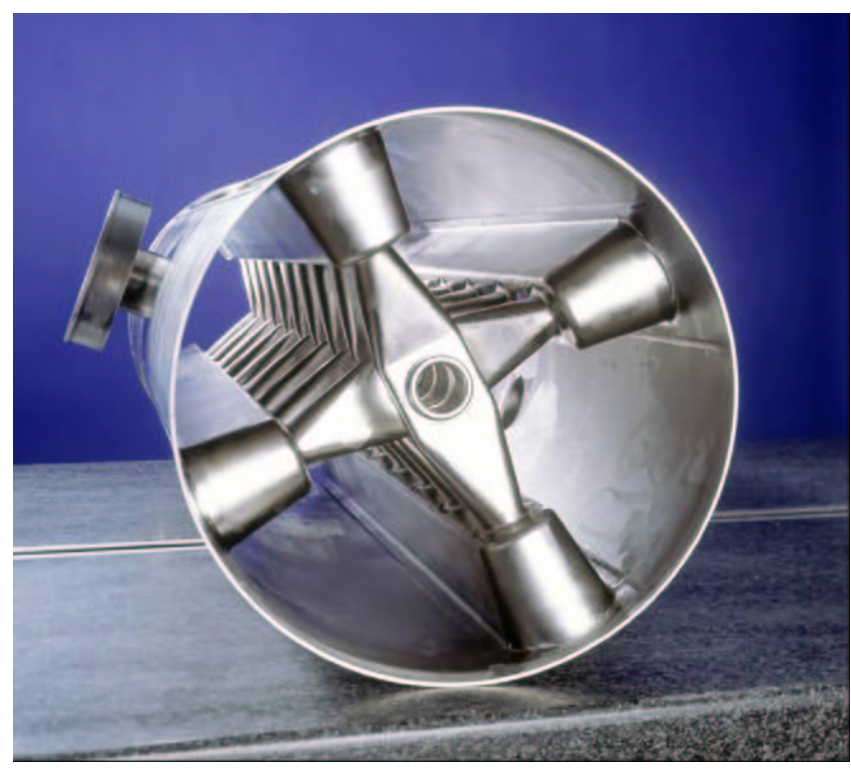

Figure 1: The superconducting $\mathrm{CH}$-structure.

All existing H-mode cavities (4-Vane-RFQ, IH-DTL and IH-RFQ) can be realized only for room temperature operation due to a lack of mechanical stability. The $\mathrm{CH}$ structure has enough mechanical stiffness for the superconducting operation. With the use of the KONUS beam dynamics [2] which reduces the transverse defocusing of

\footnotetext{
* supported by GSI, BMBF, contr. no. 06F134I and EU
}

Table 1: Parameters of the sc CH-structure
\begin{tabular}{|l|l|}
\hline parameter & value \\
\hline Gaps & 19 \\
Length & $1048 \mathrm{~mm}$ \\
Diameter & $280 \mathrm{~mm}$ \\
Frequency & $359 \mathrm{MHz}$ \\
$\mathrm{R}_{a} / \mathrm{Q}_{0}$ & $3180 \Omega$ \\
$\mathrm{G}$ & $56 \Omega$ \\
$\left(\mathrm{R}_{a} / \mathrm{Q}_{0}\right) \cdot \mathrm{G}$ & $178000 \Omega^{2}$ \\
$\mathrm{Q}_{0}\left(\mathrm{R}_{s}=150 \mathrm{n} \Omega\right)$ & $3.7 \cdot 10^{8}$ \\
$\mathrm{E}_{p} / \mathrm{E}_{a}$ & 6.16 \\
$\mathrm{~B}_{p} / \mathrm{E}_{a}$ & $7.94 \mathrm{mT} /(\mathrm{MV} / \mathrm{m})$ \\
$\mathrm{W}$ & $155 \mathrm{~mJ} /(\mathrm{MV} / \mathrm{m})^{2}$ \\
$\mathrm{P} @ \mathrm{E}_{a}=3.2 \mathrm{MV} / \mathrm{m}$ & $9 \mathrm{~W}$ \\
\hline
\end{tabular}

the beam long lensfree sections can be realized. The disadvantage of other superconducting low energy cavities like spoke or half wave resonators is the small energy gain and low real estate gradient. Due to the negative synchronous phase it is neccessary to focuse the beam frequently. Together with the required shape of the cavities this leads to more drift spaces than in $\mathrm{CH}$-structures. Additionally, due to the $\beta$-profile the $\mathrm{CH}$-structure has always the optimum transit time factor unlike 2-gap structures. The $\mathrm{CH}-$ structure is the first efficient low energy multi-cell structure with respect to real estate gradient and energy gain per cavity. It is especially suited for driver accelerators with a fixed velocity profile like XADS [3] or IFMIF [4].

Figure 1 shows the superconducting $\mathrm{CH}$-structure before the final welding of the end cells. The cavity has been fabricated by the company ACCEL [5] from 2-3 mm thick bulk niobium sheets with an RRR-value of 250 .

\section{CAVITY PARAMETERS}

Table 1 shows the main parameters of the superconducting $\mathrm{CH}$-cavity. The measured frequency is about $7 \mathrm{MHz}$ above the design value because of the weld shrinking of the tank by $2.5 \mathrm{~mm}$. Assuming a total surface resistance at $4.5 \mathrm{~K}$ of $150 \mathrm{n} \Omega$ the expected Q-value is $3.7 \cdot 10^{8}$. The required $\mathrm{rf}$ power is $9 \mathrm{~W}$ to reach the design gradient of $3.2 \mathrm{MV} / \mathrm{m}$ which corresponds to a cavity voltage of 3.36 MV. The peakfield ratio is 6.16 for the electric and $7.94 \mathrm{mT} /(\mathrm{MV} / \mathrm{m})$ for the magnetic field. This leads to moderate values $\left(\mathrm{E}_{a}=3.2 \mathrm{MV} / \mathrm{m}\right)$ for the electric and magnetic 
peak fields of $20 \mathrm{MV} / \mathrm{m}$ and $25 \mathrm{mT}$, respectively. To calculate these values, the total length of the cavity has been used.

After the fabrication of the cavity the field profile has been measured (see fig. 2). It could be demonstrated that it is possible to obtain a sufficient flat field distribution in superconducting $\mathrm{CH}$-structures. The field distribution has been optimized by changing the capacitance along the cavity locally.

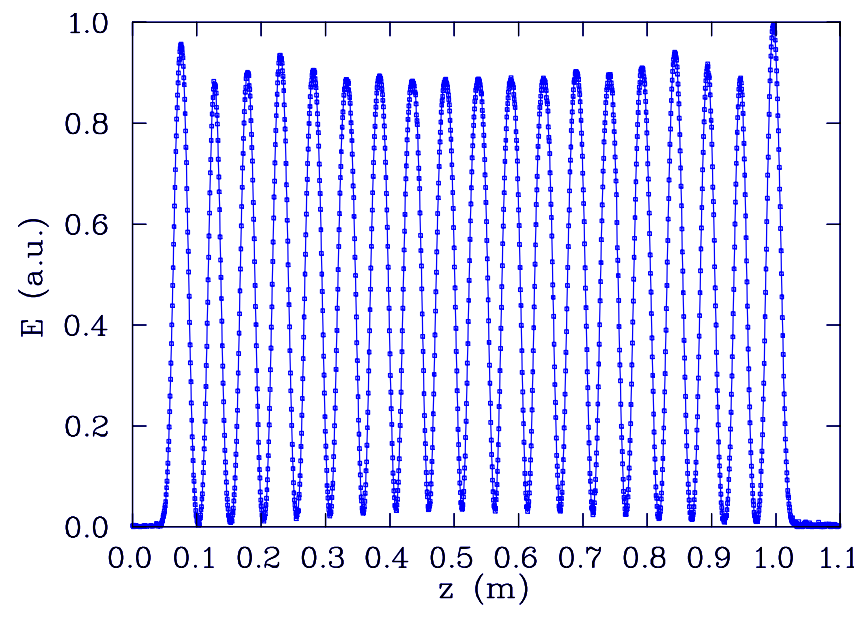

Figure 2: Measured distribution of the electric field after the final welding.

\section{RF CONDITIONING}

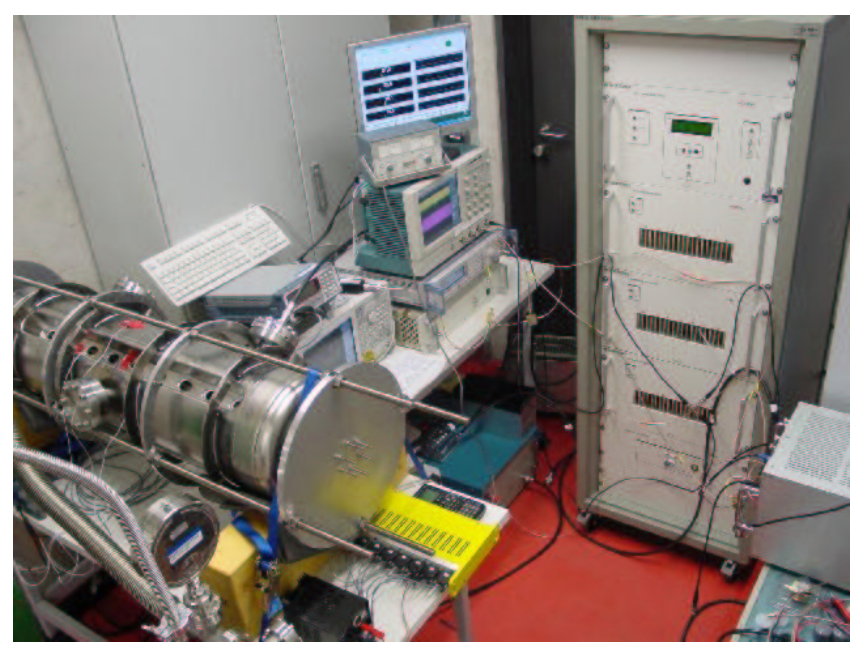

Figure 3: Experminetal setup for the room temperature rf conditioning of the $\mathrm{CH}$-structure.

Although H-mode cavites typically don't show much multipacting it has been decided to condition the $\mathrm{CH}$ structure at room temperature to reduce possible multipacting barriers. Figure 3 shows the experimental setup for the conditioning. A $2 \mathrm{~kW}$ rf-amplifier which can be operated pulsed as well as cw has been used. As input coupler a loop

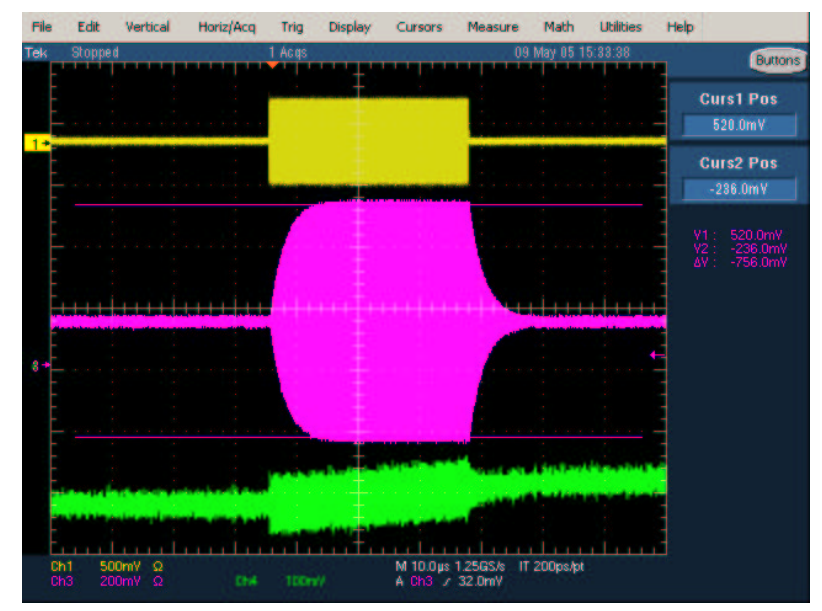

Figure 4: RF signals of the room temperture conditioning with $32 \mu \mathrm{s}, 2 \mathrm{~kW}$ pulses (forwarded power, resonator response and VCO-signal).

with $A=6 \mathrm{~cm}^{2}$ has been used. The pickup was a small coaxial coupler $\left(\mathrm{Q}_{e x t}=10^{8}\right)$ which will be used as input coupler during the crygenic tests [6]. Figure 4 shows typical rf signals during the conditioning (forwared power, pickup signal, VCO-signal). The forwarded power was $2 \mathrm{~kW}$ with a pulse length of $32 \mu \mathrm{s}$. Above $350 \mathrm{~W}$ some minor multipacting barriers have been observed. But they could be processed within one hour. The final pressure decreased from $6 \cdot 10^{-8} \mathrm{hPa}$ before the conditioning to $2 \cdot 10^{-8} \mathrm{hPa}$. Additionally, a new 8-channel temperature measurement system $(4 \mathrm{~K}-330 \mathrm{~K})$ has been installed. The temperature has been measured at different positions on the surface of the $\mathrm{CH}$-structure during an applied rf power of up to $300 \mathrm{~W}$ cw. Figure 5 shows the temperature as function of time for the different positions (top) and the $\mathrm{CH}$-cavity with the marked temperature sensors (bottom). As expected, the temperatures close to the stems (position 2 and 3) are the highest because of the highest magnetic fields and surface currents, respectively. The observed frequency shift was about $3.8 \mathrm{kHz} / \mathrm{K}$.

\section{MECHANICAL ANALYSIS}

A mechanical analysis using ANSYS [7] has been done to determine the deformation due to the external air pressure. It has been found that additional stabilization rings (see fig. 3 and 4) were neccessary to stabilize the cavity. In a second step, the mechanical eigenmodes have been calculated. The first 6 modes with support are shown in figure 6 . The frequencies are between 146 and $417 \mathrm{~Hz}$ which means that the $\mathrm{CH}$-cavity is a stiff structure. Table 2 shows the first five calculated mechanical resonances of the $\mathrm{CH}$-structure without and with mechanical support. 

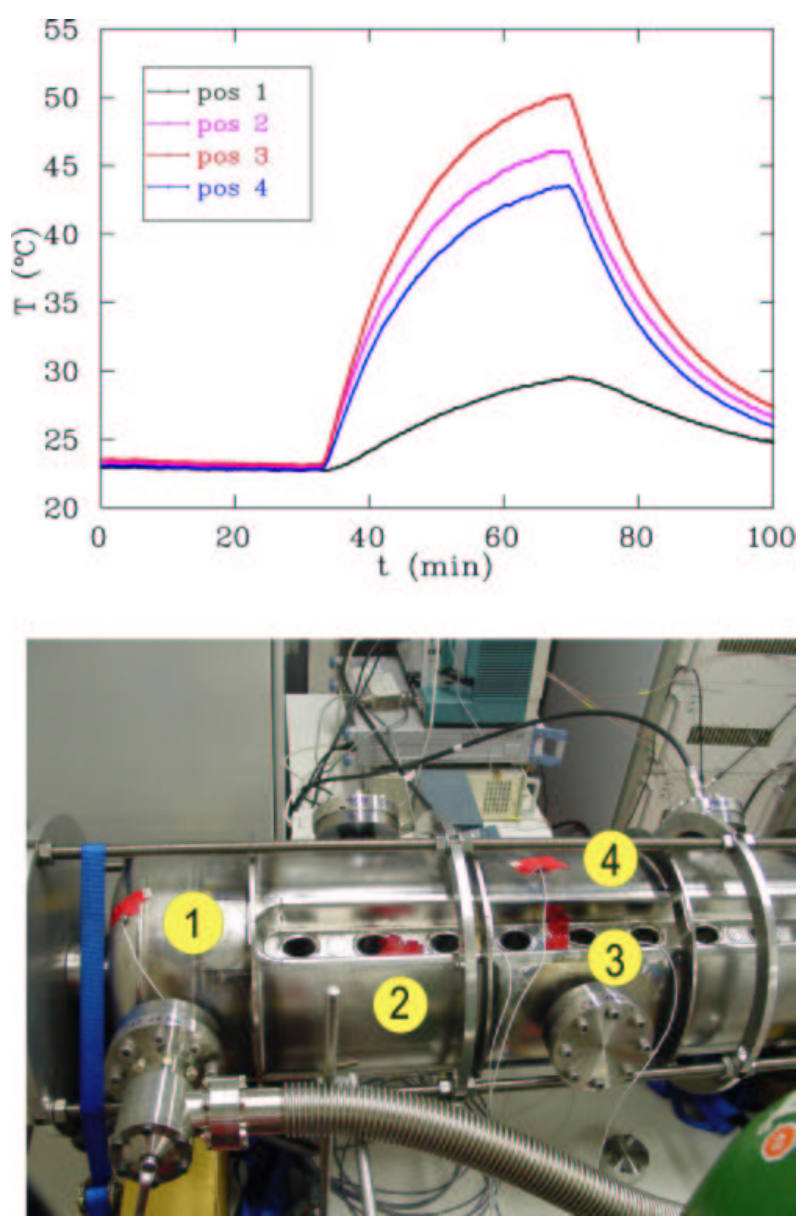

Figure 5: The temperature has been measured at 4 different positions with an rf power of $300 \mathrm{~W} \mathrm{cw}$.

Table 2: The first mechanical resonances without and with support.

\begin{tabular}{|l|l|l|}
\hline mode & without support & with support \\
\hline 1 & $229 \mathrm{~Hz}$ & $146 \mathrm{~Hz}$ \\
2 & $259 \mathrm{~Hz}$ & $228 \mathrm{~Hz}$ \\
3 & $316 \mathrm{~Hz}$ & $345 \mathrm{~Hz}$ \\
4 & $377 \mathrm{~Hz}$ & $385 \mathrm{~Hz}$ \\
5 & $532 \mathrm{~Hz}$ & $415 \mathrm{~Hz}$ \\
\hline
\end{tabular}

\section{SUMMARY AND OUTLOOK}

The superconducting $\mathrm{CH}$-structure has been delivered to the University of Frankfurt and first room temperature measurements have been performed successfully. In a next step, cold tests with helium are planned to demonstrate the performance of the $\mathrm{CH}$-structure. Additionally, simulations with respect to Lorentz force detuning, frequency shift during cool down and the determination of the stress due to a mechanical tuner will be performed.

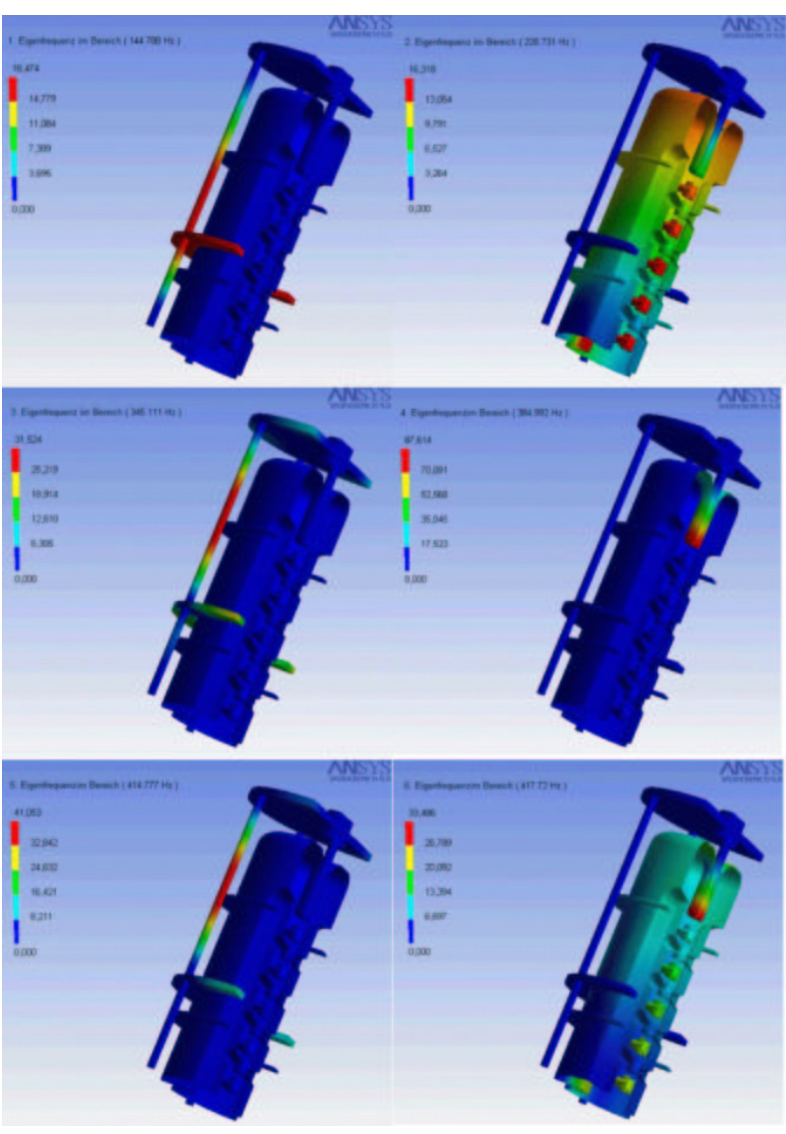

Figure 6: The first six mechanical eigenmodes of the superconducting $\mathrm{CH}$-structure calculated with ANSYS.

\section{ACKNOWLEDGEMENT}

This work has been supported by GSI, BMBF contr. No. 06F134I. and EU contr. No. EFDA/99-507ERB5005 CT990061. We acknowledge also the support of the European Community-Research Infrastructure Activity under the FP6 "Structuring the European Research Area" program (CARE, contract number RII3-CT-2003-506395) In addition, the authors would like to thank the technical staff of the IAP.

\section{REFERENCES}

[1] H. Podlech, "Development of Room Temperature and Superconducting CH-Structures", LINAC04, August 2004, Lübeck, Germany

[2] U. Ratzinger, Habilitationsschrift, Universität Frankfurt, 1998

[3] "A European Roadmap for Developing Accelerator Driven Systems (ADS) for Nuclear Waste Incineration”, April 2001, ENEA, Italy

[4] IFMIF Conceptual Design Report

[5] http://www.accel.de

[6] H. Liebermann et. al, "Coupling Methods for Room Temperature and Superconducting CH-Cavities", these proceedings

[7] http://www.ANSYS.com 